\title{
A high voltage direct current transmission system: natural and selective harmonic cancellation
}

\author{
Aziza Benaboud ${ }^{1}$, Alfred Rufer ${ }^{2}$ \\ ${ }^{1}$ ERN, Royal Navy School, Boulevard Sour Jdid, Casablanca, Morocco \\ ${ }^{2}$ EPFL, Swiss Federal Institute of Technology Lausanne, Lausanne, Switzerland
}

\begin{tabular}{l}
\hline \hline Article Info \\
\hline Article history: \\
Received Oct 23, 2018 \\
Revised Jan 2, 2019 \\
Accepted Mar 24, 2019 \\
\hline Keywords: \\
HVDC Transmission \\
Square Wave Modulation \\
NPC three level converters \\
NPC five level converters \\
Transformer connection \\
Switching angle. \\
\hline
\end{tabular}

\begin{abstract}
This study focused on the special High Voltage Direct Current technology. The context is given by combining two original solutions; the first solution, using a natural harmonic cancellation, consists to connect in series two classical frequency inverters which are coupled to the grid through a specific transformer connection. On the other hand, the second solution is achieved by using three, five or more level converters in square wave modulation, in order to eliminate some selective harmonics by optimizing a switching angle. The simulation and experimental results indicate that the proposed High Voltage Direct Current transmission systems offer high efficiency, unity power factor and better current and voltage quality with fewer harmonic.
\end{abstract}

Copyright (C) 2019 Institute of Advanced Engineering and Science. All rights reserved.

Corresponding Author:

Aziza Benaboud

Royal Navy School,

Boulevard Sour Jdid, Casablanca, Morocco

Aziza.benaboud@gmail.com

\section{INTRODUCTION}

Power electronic technology is fundamental to renewable energy systems. Many renewable resources are intermittent, and without power electronics we could not regulate voltage, frequency, and power output characteristics. Renewable sources, such as sunlight, hydrogen, and wind energy, require ACDC conversion followed by the DC-AC inverter to integrate the AC grid [1].

In this paper we present a special High Voltage Direct Current technology. It consists on the flexible exchange of power between two nodes of a network through a DC link. The conversion from AC to DC and vice versa is achieved by two classical frequency inverters in a series connection. In order to take advantage of natural harmonic cancellation, these inverters are coupled through a specific transformer connection, and their control signals are shifted by $30^{\circ}$ [2].

In addition the transformation ratio must be equal for the first transformer to 1 and for the second transformer to $\sqrt{3}[3]$.

On the other hand, a control method is also proposed to benefit from selective harmonic cancellation by using three, five or multi-level converters in square wave modulation $[4,5]$.

This paper is organized as follows. Section 2 cites some related work; session 3 lists the advantages of HVDC transmission. Section 4 describes the proposed HVDC system and shows how to benefit from natural harmonic cancellation. Section 5 proposes a control method to benefit from selective harmonic cancellation by using Multilevel NPC inverter in SWM, and Section 6 proposes the dedicated control strategy. Later in Section 7, simulation and experimental results are presented to highlight the capabilities of the proposed HVDC systems. Finally in section 8, the main conclusions of our research work as well as a discussion of their potential implications are highlighted. 


\section{RELATED WORK}

Sustainable energy generation like hydro, wind and sun will be integrated into power network all over the world as presented in Figure 1. They are normally not located close to the consumption. It will be very important to find efficient ways to transport large amounts of electricity long distances. Today, HVDC transmission seems to be the best solution of this problem [6].

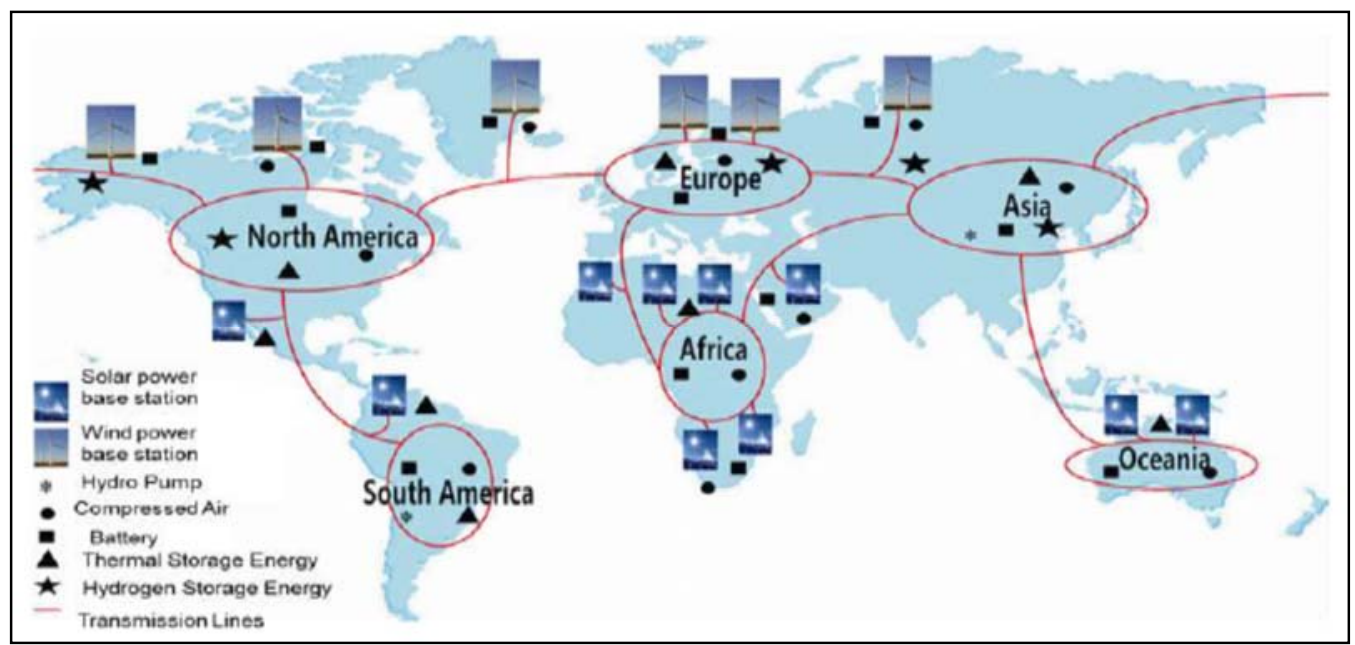

Figure 1. Power network all over the world.

It has been widely documented in the history of the industrial electricity that the first commercial electricity generated by Thomas Alva Edison was direct current electrical power. Also in 1882 when the transmission of electric energy began, it was based on direct current systems [7]. However, DC power at low voltage could not be transmitted over long distances.

In 1887, Nikola Tesla introduced a system for alternating current generators, transformers, motors, wires and light. The advantages of transmitting AC electrical energy over long distances compared to DC transmission were made clear in these very early beginnings.

During the decade of 1930s, mercury arc rectifiers were invented and DC transmission began to be considered again as an option of transmitting electrical energy, but this time at high voltage levels. In 1954, the first HVDC (10MW) transmission system was commissioned in Gotland [8].

Since the 1960s, HVDC transmission system is now a mature technology and has played a vital part in both long distance transmission and in the interconnection of systems. In 1970 HVDC transmission had a revolutionary change when thyristors were used in a converter for the first time, there are used for $\mathrm{dc}$ transmission and it is known as Current Source Converter (CSC-HVDC) [9],[10].

A new relevant step in DC transmission happened in 1990s when the Insulated Gate Bipolar Transistor (IGBT) was introduced, thus giving rise to Voltage Source Converter (VSC-HVDC) at high voltage levels [11]. This last version could be realized thanks to the resolution of the problem of the series connection of IGBT's, also due to the development of their so called press-pack version, easily insertable in large converter stacks $[12,13]$.

VSC technology allows controlling active and reactive power independently without any needs for extra compensating equipment; and brings the advantage of decoupling of harmonics between generators. However known systems of HVDC use two level inverter technology, that introduces relatively high content of harmonic voltages and currents $[14,15]$.

Important research efforts were done to cancel some harmonics or to reduce the harmonics distortion of output inverter voltage and currents, this system can fulfill the requirements of the output power quality, but with a limited value of the converters efficiency because of very high switching losses due to the high frequency of the PWM technique normally used for its control [16].

In order to take advantage of natural and selective harmonic cancellation a special High Voltage Direct Current technology is presented in this paper. The context of this contribution is given by combining two original solutions $[3,4]$.

A high voltage direct current transmission system: Natural and selective harmonic ... (Aziza Benaboud) 


\section{HVDC OR HVAC TRANSMISSION}

HVDC system allows transmitting electrical power from one point to another that are not synchronized or does not even have the same frequency. Figure 2 represents a schematic diagram of the HVDC transmission system.

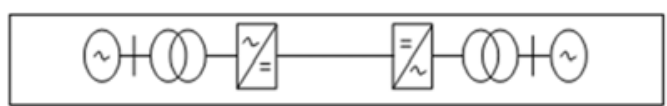

Figure 2. Schematic diagram of the HVDC transmission system

Some advantages of HDVC transmission system are: No limits in transmitted distance, this is valid for sea or underground cables. Very fast control of power flow, which implies stability improvements, not only for the HVDC link but also for the surrounding AC system. Direction of power flow can be changed very quickly; and only two conductors are needed (or even one conductor if the ground or sea is used as return) for HVDC compared to three conductors for alternating current [17].

\section{SYSTEM AND METHOD DESCRIPTION}

Figure 3 illustrates the schematic diagram of the proposed HVDC systems. It is acchieved by two frequency inverters in series connections. These frequency inverters can be configured as a three, five or more level inverters. They are coupled through a specific transformer connection, and their control signals are shifted by $30^{\circ}$.

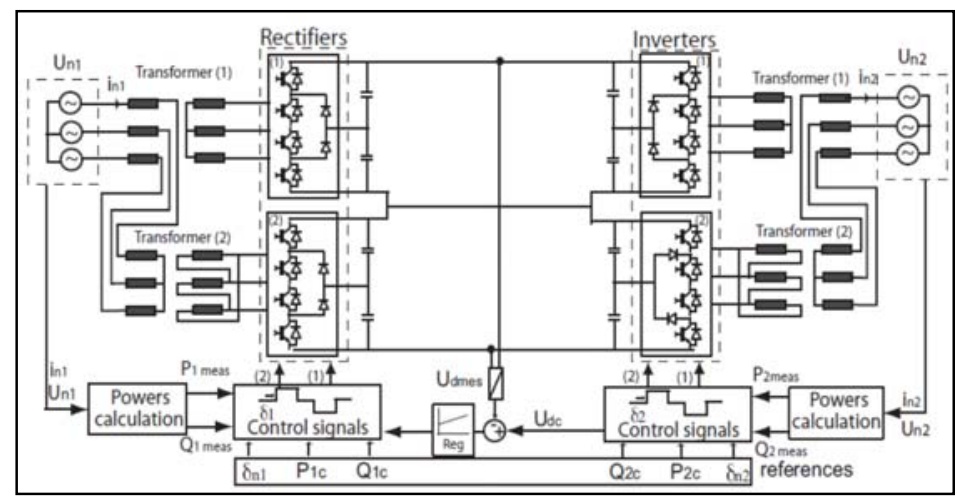

Figure 3. Schematic diagram of the proposed HVDC system with three level inverters

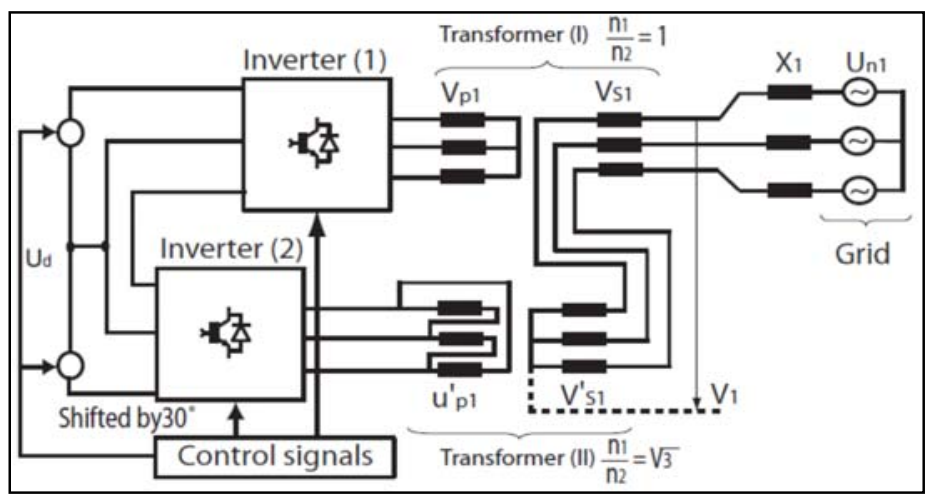

Figure 4. Schematic diagram of the proposed transformer's connection 
Figure 4 shows the transformer's connection. V' 1 1 represents the first output inverter voltage and $\mathrm{u}_{\mathrm{p} 1}$ represents the second phase to phase output inverter voltage. $\mathrm{V}_{\mathrm{s} 1}$ and $\mathrm{V}_{\mathrm{s} 1}$ are respectively the secondary voltages of transformers (I) and (II).

The transformation ratio is chosen equal for the first transformer to 1 and for the second transformer to $\sqrt{ } 3$. The output voltage is given according to (1):

$$
\left\{\begin{array}{l}
\bar{V}_{1}=\bar{V}_{\mathrm{s} 1}+\overline{\mathrm{V}}_{\mathrm{s} 1}^{\prime} \\
\overline{\mathrm{V}}_{\mathrm{s} 1}=\overline{\mathrm{V}}_{\mathrm{p} 1} \text { and } \overline{\mathrm{V}}_{\mathrm{s} 1}^{\prime}=\frac{\overline{\mathrm{u}}_{\mathrm{p} 1}^{\prime}}{\sqrt{3}} \text { with } \overline{\mathrm{u}}_{\mathrm{p} 1}^{\prime}=\overline{\mathrm{V}}_{\mathrm{p} 1}^{\prime}-\overline{\mathrm{V}}_{\mathrm{p} 2}^{\prime}
\end{array}\right.
$$

In the other hand, both inverters have the same switching angle $\delta_{\mathrm{n}}$. The output voltage is given by (2):

$$
{ }^{v} \widehat{\mathrm{V}}_{1}=\frac{4}{\sqrt{3}} \sum_{v=1}^{\infty} \frac{4}{v \pi} \mathrm{U}_{\mathrm{d}} \cos \left(\boldsymbol{v} \boldsymbol{\delta}_{\mathbf{n}}\right) \times\left(\cos (\boldsymbol{v}+1) 15^{\circ} \times \cos (\boldsymbol{v}-1) 15^{\circ}\right) \times \sin (\boldsymbol{v} \omega \mathrm{t})
$$

${ }^{v} \widehat{V}_{1}$ is represented by multiplication of two terms which depend on the harmonic $v$ and on the switching angle $\boldsymbol{\delta}_{\mathbf{n}}$. It will be equal zero when one of these terms is null:

$$
\left(\cos (\mathbf{v}+1) 15^{\circ} \times \cos (\mathbf{v}-1) 15^{\circ}\right)=0 \quad \text { or } \quad \cos \left(\boldsymbol{v} \boldsymbol{\delta}_{\mathbf{n}}\right)=0
$$

The first term of (3) is verified and can be equal to zero when: $v=6(1+2 n) \mp 1$ and $n$ must be an integer, otherwise calculated if $v=5,7,17,19,29,31, \ldots$. These harmonics are naturally cancelled. ${ }^{v} \widehat{\mathrm{V}}_{1}$ contains the fundamental $(v=1)$ and harmonics number $11,13,23, \ldots$ One or two of these harmonics can be cancelled when the second term of (3) is verified. This point will be described in the next section.

\section{MULTILEVEL NEUTRAL POINT CLAMPED INVERTER IN SWM}

\subsection{Three level NPC inverter in SWM}

A three Level Neutral Point Clamped inverter is mostly used for medium and high voltage applications.

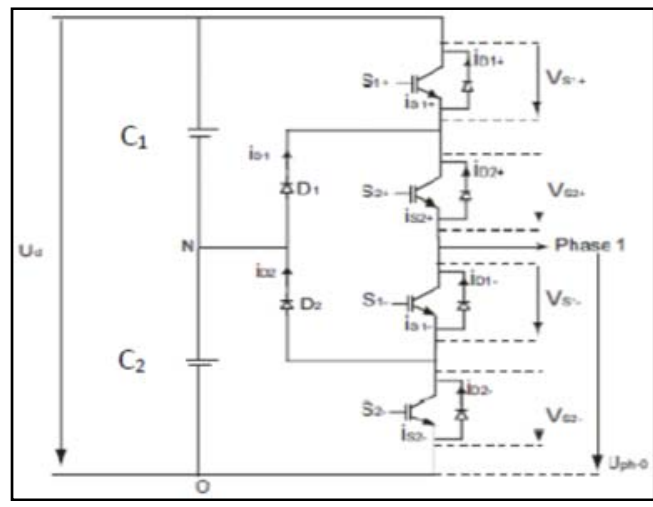

(a)

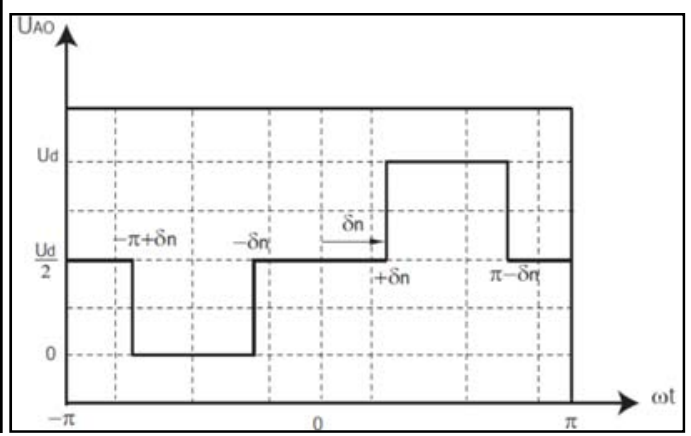

(b)

Figure 5. (a): Phase circuit diagram of a 3 level NPC inverter. (b): Output voltage's waveform of 3 level NPC inverter

Figure 5(a) shows the circuit of the Neutral Point Clamped inverter, the DC side is connected to the neutral point between capacitors via diodes to reach the third level in the output voltage. [18, 19]. Figure 5(b) shows an output-voltage's waveform of a three-level converter operated in square-wave mode. In this output voltage's waveform, $\delta_{\mathrm{n}}$ is the optimized switching angle, it can be given by (4):

$$
{ }^{v} \widehat{U}=\frac{2}{v \pi} U_{d} \cos \left(v \delta_{n}\right)
$$


The switching angle $\delta_{\mathrm{n}}$ can be selected to eliminate some harmonics. For example, the $11^{\text {th }}$ harmonic disappears when $\delta_{\mathrm{n}}=8.18^{\circ}$, or the $13^{\text {th }}$ harmonic disappears when $\delta_{\mathrm{n}}=6.92^{\circ}$. More harmonics could be eliminated together when using five or more level inverter.

\subsection{Five level NPC inverter in SWM}

A Five Level Neutral Point Clamped inverter is composed by 8 switches and connected to neutral point via diodes as illustrated in figure (6.a). The output voltage's wave form is drown in Figure (6.b). In this wave form, $\boldsymbol{\delta}_{\mathbf{n} 1}$ and $\boldsymbol{\delta}_{\mathbf{n} 2}$ present switching angles which can be chosen according to (5) in order to eliminate for example the 11 th and the 13 th harmonics together.

$$
\left\{\begin{array}{l}
{ }^{11} \widehat{U}=\frac{2 \mathrm{U}_{\mathrm{d}}}{11 \pi} \cos 11\left(\boldsymbol{\delta}_{\mathrm{n} 1}+\frac{\boldsymbol{\delta}_{\mathrm{n} 2}}{2}\right) \cos 11\left(\frac{\boldsymbol{\delta}_{\mathrm{n} 2}}{2}\right)=0 \\
{ }^{13} \widehat{\mathrm{U}}=\frac{2 \mathrm{U}_{\mathrm{d}}}{13 \pi} \cos 13\left(\boldsymbol{\delta}_{\mathrm{n} 1}+\frac{\boldsymbol{\delta}_{\mathrm{n} 2}}{2}\right) \cos 13\left(\frac{\boldsymbol{\delta}_{\mathrm{n} 2}}{2}\right)=0
\end{array}\right.
$$

Both $11^{\text {th }}$ and $13^{\text {th }}$ harmonics can be eliminated when $\delta_{\mathrm{n} 1}$ and $\delta_{\mathrm{n} 2}$ are selected to verify (5). It means $\delta_{\mathrm{n} 1}=1.26^{\circ}$ and $\delta_{\mathrm{n} 2}=13.85^{\circ}$. the THD [6].

Other optimization technique can be used to find the best combination of switching angles to reduce

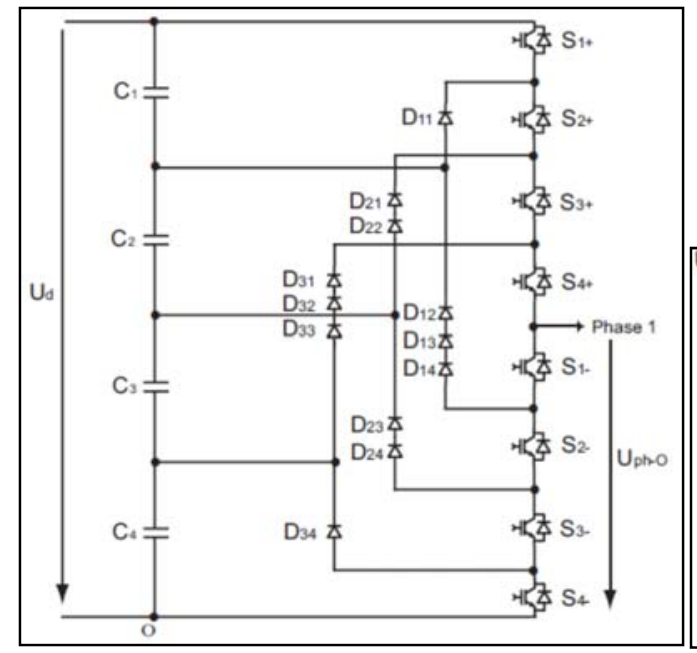

(a)

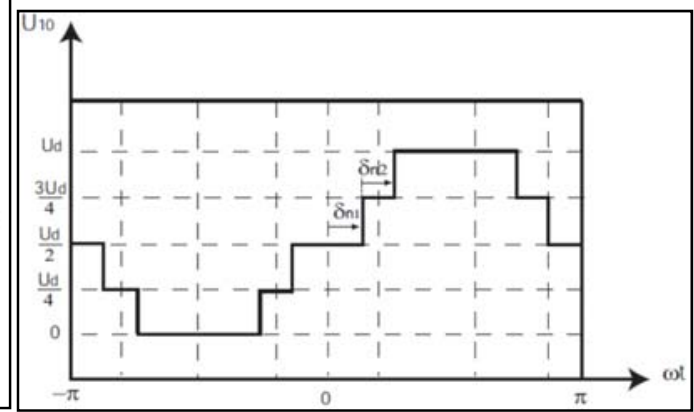

(b)

Figure 6. (a): Phase circuit diagram of a 5 level NPC inverter. (b): Output voltage's waveform of 5 level NPC inverter

\section{THE PROPOSED METHODE TO CONTROL MULTILEVEL NPC INVERTER}

In this section a control strategy is proposed for three, five or more level Neutral Point Clamped converter, characterized by its high efficiency due to the use of square-wave operation mode. The main advantage of this mode is the quasi absence of switching losses. In this mode, only the frequency can be varied between the input and the output voltages, but their magnitudes are not freely controllable. A voltage magnitude adaptation can be done by varying the DC link voltage. The produced active and reactive power can be controlled by the generator excitation as well as both the angle shift between the generator and rectifier voltages and between the inverter and network voltages, Figure 3. The capacitive intermediary circuit brings the advantage of decoupling of harmonics between the generator and the network currents [20].

Both input and output converters are controlled in the same manner. Therefore, only one side control of the output converter is described in this paper, Figure 4. 
DC voltage and the angle shift between the inverter and network voltages are given as function of active and reactive powers references and they depend on the inductance's value and the grid voltage magnitude according to (6) and (7):

$$
\begin{aligned}
\mathrm{U}_{\mathrm{dc}} & =\frac{\pi}{4 \cos \delta_{\mathrm{n}}} \sqrt{\left(\mathrm{V}_{\mathrm{n}}-\frac{2}{3} \frac{\mathrm{X}}{\mathrm{V}_{\mathrm{n}}} \mathrm{Q}_{\mathrm{nc}}\right)^{2}+\left(\frac{2}{3} \frac{\mathrm{X}}{\mathrm{V}_{\mathrm{n}}} \mathrm{P}_{\mathrm{nc}}\right)^{2}} \\
\theta_{\mathrm{nc}} & =\tan ^{-1}\left(\frac{\mathrm{P}_{\mathrm{nc}}}{\frac{3 \mathrm{~V}_{\mathrm{n}}}{2 \mathrm{x}}-\mathrm{Q}_{\mathrm{nc}}}\right)
\end{aligned}
$$

$\mathrm{X}=\mathrm{X}_{\mathrm{n}}+\mathrm{X}_{\mathrm{t}}$ With $\mathrm{X}_{\mathrm{t}}$ and $\mathrm{X}_{\mathrm{n}}$ are respectively the transformer and the network inductances.

Starting from the active and reactive powers references equal to zero (Figure 7-a), the system runs initially in no load operation, both inverter and network voltages have the same phase where the amplitude is equal to nominal. Therefore the line current is zero.

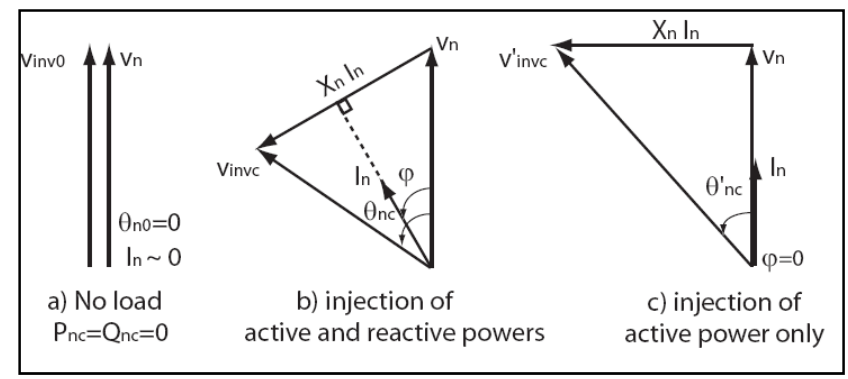

Figure 7. Diagram of voltage and current

In the first transition, the network active and reactive powers are different from zero. Consequently, the angle shift and the DC voltage change from $(\theta \mathrm{n} 0, \mathrm{Ud} 0)$ to $(\theta \mathrm{nc}, \mathrm{Udc})$ (Figure 7-b). Their values depend on the active and reactive power-references according to (6) and (7).

In the second transition, the reactive power ramps down to zero, as shown in (Figure 7-c). Consequently, the angle shift and the DC voltage must change from ( $\theta \mathrm{nc}, \mathrm{Udc})$ to $(\theta$ 'nc, U'dc). Then the reactive power can be compensated and the system can be operated using a unity power factor.

\section{EXPERIMENTAL RESULTS AND DISCUSSIONS}

The system depicted in Figure 4 has been simulated in Matlab Simulink using the following characteristics: $V_{n}=1 p u$ is the network voltage. $X_{n}=0.2 p u$ : inductance between transformers and network. Transformers characteristics: $\mathrm{L}=1 \mathrm{e}-3 \mathrm{pu}$ is Leakage inductance, $\mathrm{R}=1 \mathrm{e}-3 \mathrm{pu}$ is winding resistance. Simulation results for different switching angle $\delta_{\mathrm{n}}$ are presented;

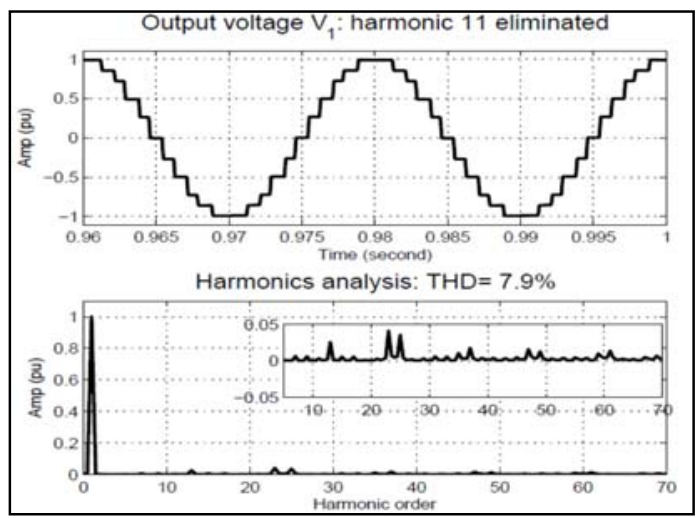

Figure 8. Transformer output voltage when $\delta_{\mathrm{n}}=8.18$

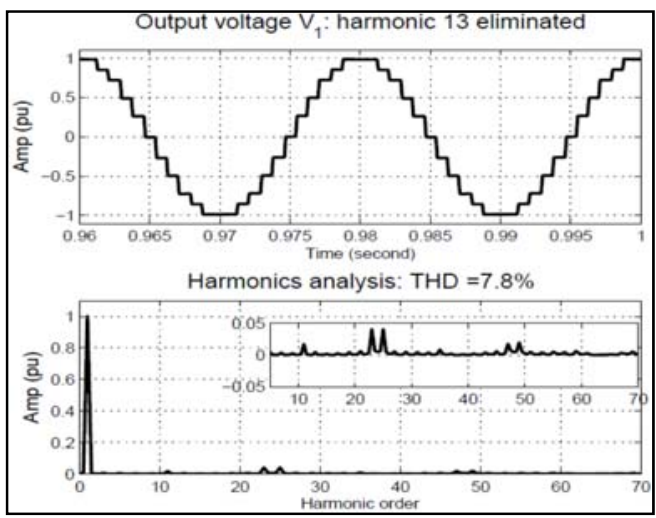

Figure 9. Transformer output voltage when $\delta_{\mathrm{n}}=6.92^{\circ}$

A high voltage direct current transmission system: Natural and selective harmonic ... (Aziza Benaboud) 
Figure 8 and Figure 9 show respectively the transformer output voltage when $\delta_{\mathrm{n}}=8.18^{\circ}$, the $11^{\text {th }}$ harmonic disappears and the case when $\delta_{\mathrm{n}}=6.92^{\circ}$ the $13^{\text {th }}$ harmonic disappears. Harmonics number $v=5,7$, $17,19,29,31, \ldots .$. are naturally cancelled. Simulation results confirm the analytics calculations done according to (2) in the previous sections.

In order to validate the dedicated control strategy, a three level frequency converter connected to the grid via inductances has been simulated. Figure 10 shows simulated active and reactive powers for different operation modes. The line current is in phase with the network voltage when the reactive power is null. The system operates with unity power factor.

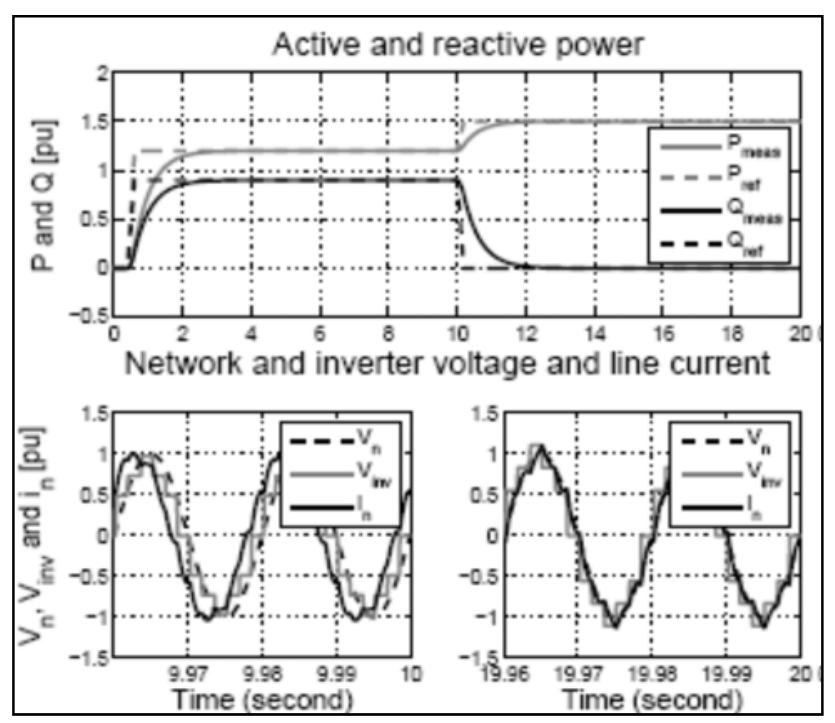

Figure 10. Simulation results: $(\cos \varphi=0.8)$ and $(\cos \varphi=1)$.

The same system has been built and tested using a low voltage laboratory prototype Figure 11.

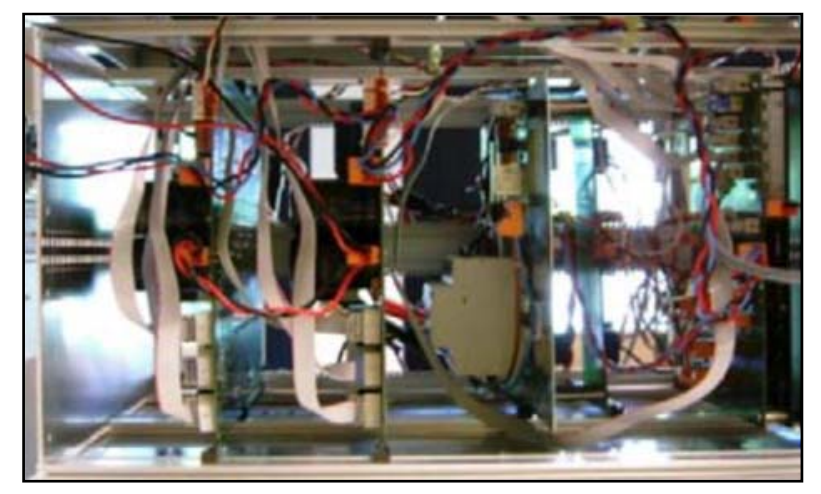

Figure 11. Laboratory prototype using 3L3PNPC inverter

Active and reactive powers are measured and presented in Figure 12 and Figure 13 together with the alternative line current, inverter and network voltages. When the reactive power is near zero, the alternative line current is in phase with the network voltage. 


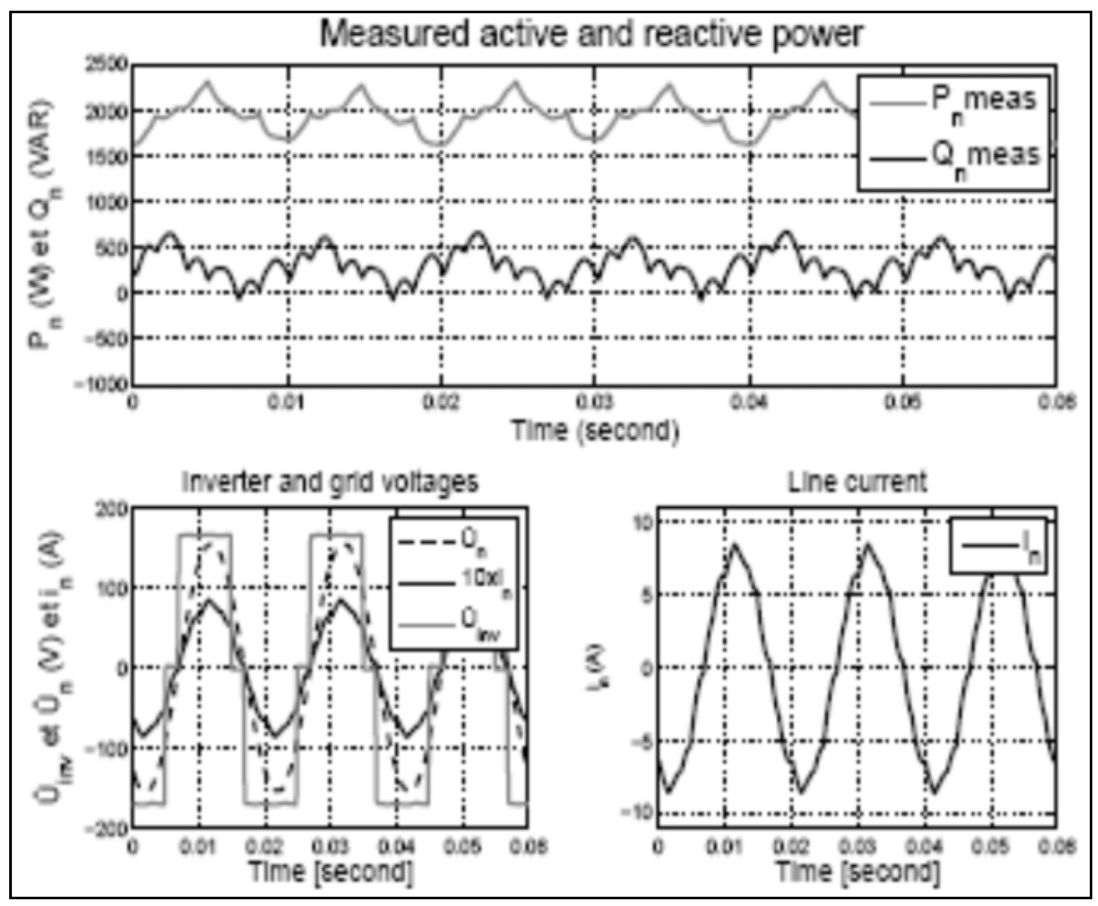

Figure 12. Practical verification results: $(\cos \varphi=1)$

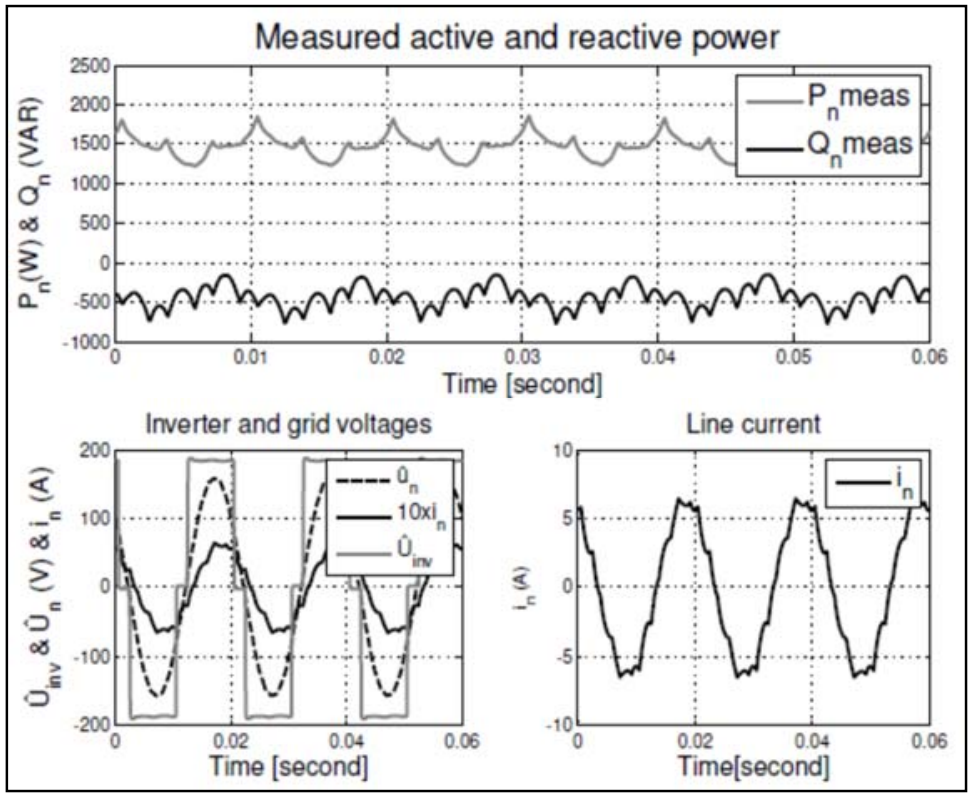

Figure 13. Practical verification results: $(\cos \varphi \neq 1)$

\section{CONCLUSION}

Sustainable energy generation is often located very far from the place where the energy will be consumed. It will be very important to find efficient ways to transport large amounts of electricity long distances. Today, HVDC transmission seems to be the best solution of this problem. Indeed, HVDC transmission systems make it possible to easily interconnect networks where voltage and frequency are not compatible, to transmit energy over long distances and they also contribute to the stability of the network thanks to their controllability in the 4 Quadrants PQ. The contribution proposed in this paper includes

A high voltage direct current transmission system: Natural and selective harmonic ... (Aziza Benaboud) 
original elements based on the combination of two solutions, to reduce the harmonics distortion of the output inverter voltage, and to operate with unity power factor and better current quality. The simulation and experimental results indicate that the proposed HVDC transmission systems offer high efficiency, and showed that with the control of the two inverters and the special coupling of the two transformers, this contribution makes it possible to take advantage of natural and selective harmonic cancellation.

\section{REFERENCES}

[1] Prasadarao VS, Joshi Manohar KV. Analysis Grid Interconnection of PV System Using Symmetric and Asymmetric MLI Topology. International Journal of Power Electronics and Drive System. 2018; 9(4): 1616-1623,

[2] Rufer A, Knapp P. Netzeinspeisung mit verlustarmem pulswechselrichter. Steuerungs elektronik, precision. 1991: 25-29.

[3] Buhler H. Convertisseurs statiques. Collection Electricité, Presses Polytechniques et Universitaires Romandes, Lausanne, 1991: 263-267.

[4] Benaboud A. Convertisseur de fréquence indirect à rapport de tension fixe: interface entre turbo-alternateurs à haute vitesse et réseau électrique. Doctoral thesis n 3733 EPFL, Lausanne, 2007.

[5] Dash SK, Nayak BA, Sahu JB. Selective Harmonic Elimination of an Eleven Level Inverter Using Whale Optimization Technique. International Journal of Power Electronics and Drive System. 2018; 9(4): 1944-1957.

[6] Tang G. High Power Conversion Technology for High Voltage DC Transmission Application. 2016 ECCE- IEEE. Milwaukee, WI, USA, Energy Conversion Congress and Exposition: 18-22.

[7] Latorre H. Modeling and Control of VSC-HVDC Transmissions. Doctoral thesis, Royal Institute of Technology School of Electrical Engineering, Electric power systems Stockholm, Sweden, 2011.

[8] Kim C, Sood V, Jang G, Lim S, Lee S. HVDC TRANSMISSION Power Conversion Applications in Power Systems. IEEE PRESS, John Wiley \&Sons (Asia) Pte Ltd.2009.

[9] Hoffmann M, Leowald K. A thyristor valve for a peak blocking voltage of $120 \mathrm{kv}$. Siemens-Zeitschrift. 1968; 42(4).

[10] Anwander E, Etter P. Thyristor converter valve for $100 \mathrm{kv}$ dc bridge voltage. Brown Boveri Mitt. 1969; 56(2).

[11] Cole S, Belmans R. Transmission of bulk power, Industrial Electronics Magazine IEEE. 2009; 3(3): 19-24.

[12] Eicher S, Rahimo M, Tsyplakov E, Schneider D, Kopta A, Schlapbach U, Carroll E. 4.5kv press pack igbt designed for ruggedness and reliability. IEEE, Industry Applications Conference, 39th IAS Annual Meeting. Seattle, WA, USA, 2004; 3:1534-1539.

[13] Asplund G.Application of HVDC light to power system enhancement. Power engineering society winter meeting IEEE. 2000; 4: 2498-2503.

[14] Gyugyi L. Reactive power generation and control by thyristor circuits. IEEE Transaction Industry Applications. 1979; 15(5): 521-532.

[15] Shalchi Alishah R, Nazarpour D, Hosseini SH, Sabahi M. Design of New Single-phase Multilevel Voltage Source Inverter. International Journal of Power Electronics and Drive System. 2014; 5(1): 45-55.

[16] Lakshmana B, Venkataratnam G. THD and Switching losses Analysis of Multi-Level Inverter Fed $3 \varphi$ Induction Motor Drive. International Journal of Scientific \& Engineering Research. 2014; 5(1): 2067-2074.

[17] Asplund G. Sustainable energy systems with HVDC transmission. IEEE Power Engineering Society General Meeting. Denver, CO, USA. 2004,

[18] Baker Richard H. Bridge converter circuit. United States Patent, 4270 163. 26 May 1981.

[19] Nabae A, Takahashi I, Akagi H. A neutral-point-clamped PWM inverter. IEEE Transactions on Industry Applications. 1981; IA(17): 518-523.

[20] Benaboud A, Rufer A. A Flexible, High efficiency, VSI-Based HVDC transmission system with reduced harmonics. Power Electronics Specialists Conference IEEE-PESC Rhodos Greece. 2008; 4117-4123. 